\title{
Fish Behaviors in Electromagnetic Fields
}

\section{Elham Foroozandeh ${ }^{1 *}$ and Pouya Derakhshan-Barjoei ${ }^{2}$}

${ }^{1}$ Department of Psychology, Naein Branch, Islamic Azad University, Naein, Iran

${ }^{2}$ Department of Telecommunication Engineering, Naein Branch, Islamic Azad University, Naein, Iran

\begin{abstract}
Electromagnetic Fields (ELFs) may change biological organisms' behaviors and brain mechanisms. There are some findings about laboratory animal's behaviors after exposure to electromagnetic fields but the findings about changes in marine especially fish are limited. In this mini review after presentation of brain structure in teleost fish, the effects of ELFs on behaviors of fish are expressed.
\end{abstract}

Keywords: Electromagnetic field; Fish

Abbreviations: EMFs: Electro-Magnetic Fields

\section{Introduction}

Electromagnetic Fields (ELFs) may change brain mechanisms [1] that lead varieties in organism behaviors [2]. In recent years some studies were focused on behavior changes in laboratory animals such as mice [3,4] and rats [5-7] after exposure to ELFs. Some kinds of learning and memory functions for example avoidance learning and spatial memory [8] are the cognitive functions that change negatively after exposure to ELFs.

One of the animal models that is considered in experimental research because of its simple neural system is fish. In this mini review, after a brief view on brain system of fish, the effects of ELFs on fish behaviors is explained.

In a general glance the parts of simple nervous system of fish are forebrain, midbrain hindbrain and other smaller parts that are shown in a schematic form in Figure 1. Olfactory bulbs and telencephalon play a crucial role in learning and conditioning specially avoidance learning and spatial awareness. Forebrain damages may result failure to memorize a maze. According to Salas et al. [9] after telencephalic ablation in goldfish ability to learning of complex place will be impaired.

The effects of ELFs on each of the parts of nervous system of fish is not clear but in the Teleost Fish these findings are reported:

1. Heart rate elevated in eels in 7 to $70 \mu \mathrm{V} / \mathrm{cm}$ electrical field and in $25 \mu \mathrm{V} / \mathrm{m}(0.025 \mathrm{~V} / \mathrm{m})$ to $15 \mathrm{~V} / \mathrm{m}$ Swam towards an electrically charged anode [10].

2. Exposure to $12,663 \mathrm{nT}$ to $192,473 \mathrm{nT}$ field exhibited significant conditioned response in Japanese eel (Anguilla japonica) [11].

3. Sensitivity to electromagnetic field was detected in European eel [12].

As Ohman et al. [13] mentioned in their study the contradictory

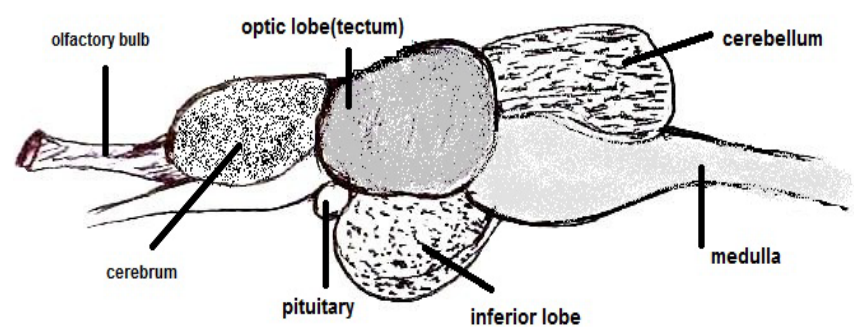

Figure 1: Schematic picture of fish brain. results in behavioral response of fishes to magnetic fields may related to different experiments and species that used in studies. Sense of magneto-reception is different in fish species and the basic abilities in spatial orientation; vision, hearing, and olfaction lead to different behaviors in electromagnetic fields.

In a study entitled "Melatonin activates brain dopaminergic systems in the eel with an inhibitory impact on reproductive function" it is stated that melatonin treatment had negative effect on reproductive function. Reproductive function of the eel needs immigration [14]. On the other hand, power frequency magnetic fields induced a marginally statistically significant increase in melatonin levels in exposed rats compared to control [15]. Based on these findings it is a hypothesis that ELFs may increase melatonin and increased level of melatonin causes delay or stop in immigration of the eel and its reproductive functions. This hypothesis and the others in the field of effects of ELFs on fish behaviors and brain parts need more experimental researches.

\section{Results and Discussion}

Because of simple neural system of fish, especially Teleost fish, it can be used in experimental research in the field of toxic effects of ELFs on different parts of brain and the behaviors that derive from each part. For instance, in fish, pituitary-gonad axis has a crucial role in sexual steroid and reproduction of fish and melatonin can disturb reproduction process. Melatonin and some of the other biological components is suggested that change after exposure to ELFs. So, it can be imagined that ELFs may change biological processes but approving these hypotheses will be after experimental research.

\section{Conclusion}

Changes in heart rate, conditioned response and immigration of some species of fish after exposure to ELFs are the recent findings about fish behaviors in ELFs. A plenty of inquiries about alteration in particular neural ways in fish brain after exposure to ELFs are for more research and certain conclusions.

*Corresponding author: Elham Foroozandeh, Department of Psychology, Naein Branch, Islamic Azad University, Naein, Iran, Tel: +98 218897 E-mail: Elham_for@yahoo.com

Received December 24, 2017; Accepted December 30, 2017; Published January 01,2018

Citation: Foroozandeh E, Derakhshan-Barjoei $P$ (2018) Fish Behaviors in Electromagnetic Fields. J Mol Biomark Diagn 9: 377. doi: 10.4172/21559929.1000377

Copyright: () 2018 Foroozandeh E, et al. This is an open-access article distributed under the terms of the Creative Commons Attribution License, which permits unrestricted use, distribution, and reproduction in any medium, provided the original author and source are credited. 
Citation: Foroozandeh E, Derakhshan-Barjoei P (2018) Fish Behaviors in Electromagnetic Fields. J Mol Biomark Diagn 9: 377. doi: 10.4172/21559929.1000377

\section{References}

1. Foroozandeh $E$ (2016) Brain changes after electromagnetic fields exposure MOJ Toxicol 2: 00036

2. Foroozandeh E, Barjoei DP, Jadidi M (2013) Toxic effects of $50 \mathrm{~Hz}$ electromagnetic field on memory consolidation in male and female mice. Toxicology and Industrial Health. 1-7.

3. Borhani N, Rajaei F, Salehi Z, Javadi A (2011) Analysis of DNA fragmentation in mouse embryos exposed to an extremely low-frequency electromagnetic field. Electromagn Biol Med 30: 246-252.

4. Halbach VBO, Zacher C, Gass P, Unsicker K (2006) Age-related alterations in hippocampal spines and deficiencies in spatial memory in mice. J Neurosci Res 83: 525-531.

5. Ozguner M, Koyu A, Cesur G, Ural M, Ozguner F, et al. (2005) Biologica and morphological effects on the reproductive organ of rats after exposure to electromagnetic field. Saudi Med J 26: 405-410.

6. Jadidi M, Firoozabadi SM, Rashidy-Pour A, Sajadi AA, Sadeghi H, et al. (2007) Acute exposure to a $50 \mathrm{~Hz}$ magnetic field impairs consolidation of spatial memory in rats. Neurobiol Learn Mem 88: 387-392.

7. Vazquez-Garcıa M, Elıas-Vinas D, Reyes-Guerrero G, Domınguez-Gonzalez A, Verdugo-Diaz L, et al. (2004) Exposure to extremely low-frequency electromagnetic fields improves social recognition in male rats. Physiology \& Behaviour 82: 685-690.
8. Foroozandeh E (2015) Electromagnetic fields and spatial memory. MOJ Toxicol 1: 00015.

9. Salas C, Rodriguez F, Vargas JP, Duran E, Torres B (1996) Spatial learning and memory deficits after telencephalic ablation in goldfish trained in place and turn maze procedures. Behav Neurosci. 110: 1-16.

10. Marino AA, Becker RO (1977) Biological effects of extremely low frequency electric and magnetic fields: A review. Physiolo Chem Phys 9: 131-148.

11. Nishi T, Kawamura G, Matsumoto K (2004) Magnetic sense in the Japanese eel, Anguilla japonica, as determined by conditioning and electrocardiography. J Experimental Bio 207: 2965-2970.

12. Tesch FW, Wendt T, Karlsson L (1992) Influence of geomagnetism on the activity and orientation of eel, Anguilla anguilla, as evident from laboratory experiment. Aq Ecol Freshw Fish 1: 52-60.

13. Ohman MC, Sigray P, Westerberg $H$ (2007) Offshore windmills and the effects of electromagnetic fields on fish. Ambio 36: 8.

14. Sébert ME, Legros C, Weltzien FA, Malpaux B, Chemineau P, et al. (2008) Melatonin activates brain dopaminergic systems in the eel with an inhibitory impact on reproductive function. J Neuroendocrinology 20: 917-929.

15. Dyche J, Anch AM, Fogler KAJ, Barnett DW, Thomas C (2012) Effects of power frequency electromagnetic fields on melatonin and sleep in the rat. Emerg Heal Thr J 5: 10904 